\title{
JUKMAS
}

Jurnal Untuk Masyarakat Sehat (JUKMAS)

e-ISSN : 2715-7687

Vol. 4, No. 1 April 2020

P-ISSN : 2715-8748

\section{Hubungan Kualitas Pelayanan Terhadap Kepuasan Pasien Medichal Check Up di Klinik Medika Plaza Kecamatan Pasar Minggu Jakarta Selatan Tahun 2019}

\author{
Robo Marliana Rahayu, Sri Siswani \\ Fakultas Kesehatan Masyarakat, Universitas Respati Indonesia \\ Email : marliana_rahayus87@gmail.com
}

\begin{abstract}
ABSTRAK
Kualitas pelayanan merupakan bentuk penilaian konsumen terhadap tingkat pelayanan yang diterima (Perceived Cervice) dengan tingkat pelayanan yang diharapkan (expected cervice). Tujuan dari penelitian ini adalah untuk mengetahui gambaran hubungan kualitas pelayanan aspek responsiveness terhadap loyalitas pelanggan MCU di klinik Medika Plaza kecamatan Pasar minggu Jakarta Selatan tahun 2019. Penelitian ini merupakan penelitian survey analitik dengan rancangan potong lintang (cross sectional). Penelitian dilakukan di Klinik Medika Plaza Pasar Minggu pada bulan juni - Juli 2019. Pengambilan sampel penelitian ini didapatkan dengan menggunakan metode total sampling, dimana seluruh pasien MCU menjadi sampel penelitian sebanyak 88 orang responden. Hasil penelitian menunjukkan bahwa antara proporsi jumlah pasien yang loyal dan tidak loyal tidak terlalu besar, dimana pasien yang berpotensi loyal dengan pelayanan MCU di klinik medika plaza sebanyak 48 orang $(54,5 \%)$ dan yang tidak loyal sebanyak 40 orang $(45,5 \%)$. Responsiveness berdasarkan aspek waktu tunggu, kemudahan layanan registrasi, keramahan, kemudahan informasi dan kenyamanan diperoleh $p$-value 0.001 dimana $p$ value $\leq a(0,05)$, yang artinya ada hubungan yang signifikan antara variabel tersebut terhadap loyalitas pasien medical check up.
\end{abstract}

kata Kunci : Kualitas Pelayanan, Loyalitas, Kepuasan Pasien

\section{ABSTRACT}

Service quality is a form of consumer assessment of the level of service received (Perceived Cervice) with the level of service expected (expected cervice). The purpose of this study is to find out the relationship between the quality of service aspects of responsiveness to MCU customer loyalty at the Medika Plaza clinic Pasar Minggu subdistrict of South Jakarta in 2019. This research is an analytic survey research with cross sectional design. The study was conducted at the Pasar Medika Plaza Pasar Minggu in June - July 2019. Sampling of this study was obtained using a total sampling method, where al MCU patients were sampled as many as 88 respondents. The results showed that the proportion of the number of loyal and non-loyal patients was not too large, where the patients who were potentially loyal to the MCU service at the Medika Plaza clinic were 48 people (54.5\%) and those who were not loyal as many as 40 people (45.5\%). Responsiveness based on aspects of waiting time, ease of registration services, friendliness, ease of information and convenience obtained $p$-value 0.001 where $p$ value $\leq$ a (0.05), which means that there is a significant relationship between these variables on the loyalty of medical check-up patients.

Keywords: Service Quality, Loyalty, Patient Satisfaction 


\section{PENDAHULUAN}

Pelayanan kesehatan (health care service) merupakan hak setiap orang yang dijamin dalam Undang Undang Dasar 1945 untuk melakukan upaya peningkatkan derajat kesehatan baik perseorangan, maupun kelompok atau masyarakat secara keseluruhan. Defenisi Pelayanan kesehatan menurut Departemen Kesehatan Republik Indonesia Tahun 2009 (Depkes RI) yang tertuang dalam Undang Undang Kesehatan tentang kesehatan ialah setiap upaya yang diselenggarakan sendiri atau secara bersama-sama dalam suatu organisasi untuk memelihara dan meningkatkan kesehatan, mencegah dan menyembuhkan penyakit serta memulihkan kesehatan, perorangan, keluarga, kelompok ataupun masyarakat. Berdasarkan Pasal 52 ayat (1) UU Kesehatan.

Dengan penerapan layanan kesehatan, kepuasan pasien menjadi bagian yang integral dan menyeluruh dari kegiatan layana kesehatan, artinya pengukuran tingkat kepuasan pasien menjadi kegiatan yang tidak dapat dipisahkan dari layanan kesehatan (pohan,2007) kepuasan pasien menjadi tempat tersendiri dan merupakan hal yang sangat penting untuk peningkatkan kualitas lananan kesehatan. Kepuasan kan terjadi apabila harapan dari pasien dapat dipenuhi dari pelayanan yang diberikan oleh perusahaan jasa layanan kesehatanhingga perlu diperhatikan dan dievaluasi secara terus menerus kepuasan dan harapan dari pasien (Setiawan,2011).

Indikasi kualitas pelayanan kesehatan dapat tercermin dari persepsi pasien atas layanan kesehatan yang telah diterimanya. Persepsi pasien atau pelanggan tentang kualitas pelayanan merupakan penilaian menyeluruh atas keunggulan suatu jasa atau pelayanan (Tjiptono,2012).

Kualitas pelayanan tercermin dari loyalitas pasien untuk menggunakan jasa kesehatan pelaksanaan medical check up secara berkala menimal satu tahun sekali. Pada Medical check up dirumah sakit/ klinik menggunakan pelayanan untuk pemeriksaan kesehatan terdiri dari dokter ahli yang juga di dudukung oleh penunjang medis lainnya. Setiap rumah sakit/ klinik juga dikhususkan di Medicak Check up dituntut untuk meningkatkan kinerja pegawai agar dapat lebih baik. Selain itu, kualitas pelayanan memudahkan dalam bertransaksi dari kecepatan respon dan menangani keluhan merupakan faktorfaktor yang sangat dipertimbangkan pasien dalam memilih jasa untuk kesehatan pasien. Apalagi hal ini bersangkitan lansung mengenai kesehatan tubuh pasien tentu keamanan dan kenyamanan faktor 
penting bagi pasien karena banyak saat ini terjadinya malpraktek rumah sakit yang sangat mengkwatiran pasien. Keamaan dan kenyamanan juga termasuk hal penting pada sebuah perusahan jasa layanan kesehatan.

Mengingat peran MCU sangat penting dan semakin banyanya competitorcompetitor maka sudah selayaknya klinik medika plaza memberikan perhatian terhadap peningkatan mutu pelayanan agar pasien tidak beralih ke tempat lain. Fenomena ini sangat berkaitan dengan loyalitas pasien, karena pada dasarnya setiap individu sangat menginginakan pelayanan yang dirasa pas di setiap hati. jika pasien senang dan puas pelayanan yang diberikan, maka pasien pastilah nyaman dan akan percaya untuk loyal menginvestasikan kesehatan mereka dan merasa memiliki ikatan kuat dengan klinik Medika Plaza. Pasien yang loyal alat promosi yang efektif. Dengan adanya pasien yang loyal akan sangat membantu klinik Medika Plaza jika meraka loyal, pasien pun tidak lagi mementingkan harga namun mereka mungutamakan apa yang akan mereka terima dan apa yang mereka dapatkan seperti sebuah kenyamanan dan kepuasan mereka, juga mereka yang royal sangat membantu pihak Klinik Medika Plaza promosi dari mulut ke mulut di masyarakat luas, dimana masyarakat lain juga akan terpengaruh untuk mengujungi dan mempercayakan mengenai kesehatan mereka ke klinik Medika Plaza. Upaya dari klinik Medika Plaza adalah bagaimana membuat pasien loyal atau setia dan percaya kepada rumah sakit. Bagi klinik Medika Plaza yang terpenting adalah bagaimana proses dan mekanisme mencapai loyalitas pasien.

Untuk menciptakan loyalitas pasien yang dibutuhkan tidak hanya value dan brand tapi juga harus ada hubungan erat dan baik pada setiap pasien. Mempertahankan pasien maupun intansi lainya dapat dilakukan dengan strategi pemasaran yakni memberikan kepuasan pasien atau intansi laiinya, sehingga akan lebih sulit bagi saingan untuk menawarkan jasa mereka. Persaingan dalam hal yang positif akan membuat suatu perusahaan bersaing yang sehat. Untuk itu perusahan dapat menyusun strategi pelayanan yang baik untuk kepuasan pelanggan maupun pasien.

Menjalin hubungan yang baik pada setiap pasien dapat menjamin kelangsungan hidup sebuah pemberi jasa layanan, karena apabila pasien tidak mempercayakan kesehatan mereka pada bagian ini maka tidak akan menjadi pilihan pasien dan tidak akan berjalan baik. Mengacu pada latar bekang diatas maka penulis akan meneliti klinik medika plaza bukan hanya memberikan pelayana medical check up untuk induvidu tetapi 
untuk karyawan-karyawan intansi maupun perusahan perusahaan besar di Indonesia, seperi BP, exxon, petronas, Unilever dll.

Klinik Medical Check Up Medika Plaza selalu berusaha memberikan pelayanan yang sesuai dengan harapan bahkan lebih dari yang diharapakan pasien dengan fasilitas-fasilitas dan penunjang medis lainnya yang mungkin tidak dimiliki oleh Medical check Up rumah sakit lainya yang tak lain ingin mempertahan kan dan membuat kepercayaan bagi setiap intansi pasien untuk melakukan pencheck up an kesehatan. Dalam menjaga hubungan dan kepercayaan pasien Medical Check Up Klinik Medika Plaza berusaha agar tetap memuaskan dan menjaga kepercayaan yang diberikan hal ini dapat dilakukan dengan meningkatkan sevise atau pelayanan yang diberikan kepada pasien.

Mutu pelayanan menjadi dorongan bagi para pelanggan untuk menjali relasi. Hal tersebut tentunya membutuhkn peran aktif dari pegawai untuk wajib memakai baju seragam rapi agar terlihat kompak, pegawai juga diwajibkan untuk memberikan sapaan dan senyum bagi pelanggan dan pegawai siap untuk melayani kebutuhan pelanggan secara cepat dan tepat. Yang masih sering menjadikan complain tentang pelayanan MCU tahun 2018 adalah seperti ketidak jelasan waktu tunggu pemeriksaan, waktu tunggu registrasi dan kesigapan petugas registrasi, layanan dokter spesialis yang tidak pasti, sarana pendukung seperti tempat ganti baju yang kurang nyaman dan tergabung dengan toilet

Berdasarkan uraian tersebut, peneliti tertarik untuk mengadakan penelitian tentang" hubungan kualitas pelayanan aspek Resonsiveness pada loyalitas pelanggan Medical Chek Up (MCU) di Kinik Medika Plaza Pasar Minggu Jakarta Selatan Tahun 2019". Diharapkan dengan mengetahui hubungan tersebut dapat menjadi masukan dan pertimbangan bagi pihak Medika Plaza untuk mempertahankan serta meningkatkan pelayanan Medical Check Up.

\section{METODE PENELITIAN}

Penelitian ini merupakan penelitian survey analitik dengan rancangan potong lintang (cross sectional), dengan rancangan ini informasi mengenai lima dimensi kualitas pelayananan yaitu tangble, reliability, responsiveness, assurance dan empathy sebagai variable independen diperoleh secara bersamaan dengan hubungannya dengan kepuasan pasien Medical Check Up (MCU).

Lokasi penelitian ini adalah di Klinik Medika Plaza Pasar Minggu, Jakarta Selatan. Waktu Penelitian dilakukan pada bulan juni - Juli 2019

Instrument yang digunakan dalam penelitian ini adalah dengan menggunakan 
Jurnal Untuk Masyarakat Sehat (JUKMAS)

angket (kuesioner) yang akan disebarkan kepada responden. Untuk memperoleh informasi dari reponden, peneliti menggunakan lembar kuesioner yang disusun secara terstruktur berdasarkan teori dan berisikan pertanyaan yang harus dijawab oleh responden.

Pengambilan sampel penelitian ini didapatkan dengan menggunakan metode total sampling, dimana seluruh pasien MCU menjadi sampel penelitian sebanyak 88 orang

responden

\section{HASIL PENELITIAN}

\subsection{Analisis Univariat}

Tabel 1 Analisis Univariat

\begin{tabular}{|c|c|c|c|}
\hline No & Variabel & $\begin{array}{c}\text { Jumlah } \\
\text { (n) }\end{array}$ & $\begin{array}{c}\text { Persentase } \\
(\%)\end{array}$ \\
\hline \multirow[t]{4}{*}{1} & Loyalitas & & \\
\hline & Pasien & & \\
\hline & Loyal & 48 & 54.5 \\
\hline & Tidak Loyal & 40 & 45.5 \\
\hline \multirow[t]{3}{*}{2} & Waktu Tunggu & & \\
\hline & Baik & 43 & 48.9 \\
\hline & Tidak Baik & 45 & 51.1 \\
\hline \multirow[t]{5}{*}{3} & Kemudahan & & \\
\hline & Layanan & & \\
\hline & Registrasi & & \\
\hline & Baik & 38 & 43.2 \\
\hline & Tidak Baik & 50 & 56.8 \\
\hline \multirow[t]{3}{*}{4} & Keramahan & & \\
\hline & Baik & 46 & 52.3 \\
\hline & Tidak Baik & 42 & 47.7 \\
\hline \multirow[t]{4}{*}{5} & Kemudahan & & \\
\hline & Informasi & & \\
\hline & Baik & 51 & 58 \\
\hline & Tidak Baik & 37 & 42 \\
\hline \multirow[t]{3}{*}{6} & Kenyamanan & & \\
\hline & Baik & 44 & 50 \\
\hline & Tidak Baik & 44 & 50 \\
\hline
\end{tabular}




\subsection{Analisis Bivariat}

Tabel 2 Analisis Bivariat

\begin{tabular}{|c|c|c|c|c|c|c|c|c|c|}
\hline \multirow{3}{*}{ No } & \multirow{3}{*}{ Variabel } & \multicolumn{4}{|c|}{ Loyalitas Pasien } & \multirow{2}{*}{\multicolumn{2}{|c|}{ Total }} & \multirow{3}{*}{$\begin{array}{c}\mathrm{P} \\
\text { value }\end{array}$} & \multirow{3}{*}{$\begin{array}{c}\text { OR } \\
(95 \%-\mathrm{Cl})\end{array}$} \\
\hline & & \multicolumn{2}{|c|}{ Loyal } & \multicolumn{2}{|c|}{ Tidak Loyal } & & & & \\
\hline & & $\mathrm{n}$ & $\%$ & $\mathrm{n}$ & $\%$ & $\mathrm{n}$ & $\%$ & & \\
\hline \multirow[t]{3}{*}{1} & Waktu Tunggu & & & & & & & \multirow{3}{*}{0,001} & 0,195 \\
\hline & Baik & 15 & 34,9 & 28 & 65,1 & 43 & 100 & & $(0,078-$ \\
\hline & Tidak Baik & 33 & 73,3 & 12 & 26,7 & 45 & 100 & & $0,484)$ \\
\hline \multirow[t]{4}{*}{2} & Kemudahan & & & & & & & \multirow[t]{4}{*}{0,003} & 4,200 \\
\hline & Layanan Registrasi & & & & & & & & $(1,678-$ \\
\hline & Baik & 28 & 73,7 & 10 & 65,1 & 38 & 100 & & $10,511)$ \\
\hline & Tidak Baik & 20 & 40,0 & 30 & 26,7 & 50 & 100 & & \\
\hline \multirow[t]{3}{*}{3} & Keramahan & & & & & & & \multirow[t]{3}{*}{0,000} & 15,200 \\
\hline & Baik & 38 & 82,6 & 8 & 17,4 & 46 & 100 & & $(5,563-$ \\
\hline & Tidak Baik & 10 & 23,8 & 32 & 76,2 & 42 & 100 & & $43,084)$ \\
\hline \multirow[t]{4}{*}{4} & Kemudahan & & & & & & & \multirow[t]{4}{*}{0,000} & 24,111 \\
\hline & Informasi & & & & & & & & $(7,770-$ \\
\hline & Baik & 42 & 82,4 & 9 & 17,6 & 51 & 100 & & $74,823)$ \\
\hline & Tidak Baik & 6 & 16,2 & 31 & 83,8 & 37 & 100 & & \\
\hline \multirow[t]{3}{*}{5} & Kenyamanan & & & & & & & \multirow[t]{3}{*}{0,000} & 12,000 \\
\hline & Baik & 36 & 81,8 & 8 & 18,2 & 44 & 100 & & $(4,356-$ \\
\hline & Tidak Baik & 12 & 27,3 & 32 & 72,7 & 44 & 100 & & $33,061)$ \\
\hline
\end{tabular}

\section{PEMBAHASAN}

\subsubsection{Hubungan antara waktu tunggu} dengan loyalitas pasien

Hasil analisis hubungan antara loyalitas pasien dengan pelayanan waktu tunggu diperoleh bahwa dari 48 reponden yang akan loyal dengan pelayanan MCU, ada sebanyak 15 responden $(34,9 \%)$ yang menyatakan waktu tunggu layanan baik sedangkan yang menyatakan waktu tunggu layanan tidak baik ada 33 responden $(73,3 \%)$, artinya nilai kualitas waktu tunggu tidak baik lebih dari setengah pasien layanan waktu tunggu tidak baik yang meliputi waktu tunggu proses registrasi, kecepat dan kecepatan, waktu tunggu dokter spesialis dan antrian unit layanan yang masih belum efisien sehingga beresiko pasien tidak loyal untuk MCU kembali ke klinik Medika Plaza

Hasil uji statistic hubungan antara waktu tunggu dengan loyalitas pasien medical check up diperoleh $p$-value 0.001 dimana $p$ value $\leq a(0,05)$, yang artinya ada hubungan yang signifikan antara layanan waktu tunggu terhadap loyalitas pasien medical check up. Nilai OR 0,195 artinya responden menyatakan layanan waktu tunggu yang baik mempunyai peluang 1 kali lebih loyal dibandingkan dengan 
responden yang menyatkan waktu tunggu tidak baik.

Hasil penelitian ini sesui menurut Jelvi Sitayani (2010) dimana hasil uji statistic diperoleh $p$ value $=0,000$ yang artinya ada hubungan signifikan antara kepuasan pasien dengan loyalitas pasien rawat jalan. Demikian juga menurut penelitian Dwi Zaniarti dimana hasil uji statistic diperoleh nilai $p=0$, 000 dimana nilai $P \leq 0,01$ yang artinya ada hubungan signifikan antara pelayanan dengan loyalitas pasien.

Menurut Daryanto \& Setyobudi 2014 salah satu mutu pelayanan adalah tepat waktu. Secara utuh dan prima petugas pelayanan dalam memberikan layanan perlu diperhitungkan durasi dan pelayanan yang cepat dan tepat.

\subsubsection{Hubungan antara kemudahan} layanan registrasi dengan loyalitas pasien

Hasil analisis hubungan antara loyalitas pasien dengan kemudahan layanan registrasi yang baik diperoleh bahwa dari 48 reponden yang akan loyal dengan pelayanan MCU, ada sebanyak 28 responden $(73,7 \%)$ yang menyatakan waktu tunggu layanan baik sedangkan yang menyatakan waktu tunggu layanan tidak baik ada 20 responden $(40,0 \%)$, artinya system registrasi sudah berjalan baik, meskipun ada sebagian pasien yang menyatakan tidak baik, Petugas resgistrasi memberikan pelayanan yang memudahkan pelanggan melakukan medical Check Up diantaranya petugas sudah menerima surat jaminan dari perusahaan, paket pemeriksaan sudah terinput oleh tim admin marketing dan pasien sudah tercatata dalam daftar apoitmen system register, yang sering di keluhkan oleh pasien adalah proses registrasi tidak bisa online, sehingga pasien harus berburu waktu untuk mendapatkan antrian dengan nomor urut terkecil

Hasil uji statistic hubungan antara kemudahan layanan registrasi dengan loyalitas pasien medical check up diperoleh $p$-value 0.003 dimana $p$ value $\leq a(0,05)$, yang artinya ada hubungan yang signifikan antara kemudahan layanan registrasi terhadap loyalitas pasien medical check up. Nilai OR 4,200 artinya responden menyatakan kemudahan layanan registrasi yang baik mempunyai peluang 4 kali lebih loyal dibandingkan dengan responden yang menyatkan waktu tunggu tidak baik.

Hasil penelitian ini diperkuat oleh penelitian Ertika Sekarningrum 2016 dimana hasil uji statistic diperoleh $p$ value $=0,000$ yang artinya ada hubungan signifikan antara kemudahan layanan dengan loyalitas 
pasien di unit rawat inap RSUD kota kendari. Demikian juga menurut penelitian dari Raden Chandra 2010 dimana diperoleh $p$ value 0,002 dengan OR 5,4. Berarti $P$ value $<_{-}(0,05)$, ini bermakna bahwa terdapat hubungan kepuasan secara umum dengan loyalitas responden. Odd Ratio 5,4 bermakna bahwa responden yang menyatakan puas memiliki probabilitas 5 kali dinyatakan loyal.

Menurut Daryanto \& Setyobudi 2014 salah satu mutu pelayanan adalah kesediaan melayani. Secara utuh dan prima petugas pelayanan dalam memberikan kemudahan pelanggan untuk mendapatkan pelayanan.

\subsubsection{Hubungan antara keramahan} petugas dengan Loyalitas pasien

Hasil analisis hubungan antara loyalitas pasien dengan keramahan petugas diperoleh bahwa dari 48 reponden yang akan loyal dengan pelayanan $\mathrm{MCU}$, ada sebanyak 38 responden $(82,6 \%)$ yang menyatakan keramahan petugas baik, sedangkan yang menyatakan keramahan petugas tidak baik ada 10 responden $(23,8 \%)$. Yang berarti bahwa petugas sudah memberikan tingkat keramahan yang baik dimana rasa peduli dan perhatian yang cukup kepada pasien. Hal ini tidak berdampak begitu besar, dimana hasil penelitian responden yang menyatakan baik lebih besar daripada yang menyatakan tidak baik.

Hasil uji statistic hubungan antara keramahan petugas dengan loyalitas pasien medical check up diperoleh $p$-value 0.000 dimana $p$ value $\leq a(0,05)$, yang artinya ada hubungan yang signifikan antara keramahan petugas terhadap loyalitas pasien medical check up. Nilai OR 15,200 artinya responden menyatakan keramahan petugas yang baik mempunyai peluang 15 kali lebih loyal dibandingkan dengan responden yang menyatkan waktu tunggu tidak baik.

Hasil analisa diperkuat oleh penelitian Raden Chandra (2010) dimanana hasil uji statistic diperoleh $p$ value $=0,002$ yang artinya ada hubungan yang signifikan antara kepuasan secara umum dengan loyalitas responden demikian penelitian menurut Mohammad Nurul Hidayah Hasil uji statistik diperoleh nilai $p=0,000$ $(<0,05)$ maka Ho ditolak yang artinya ada hubungan antara empathy dengan loyalitas.

Menurut

Tjiptono,2012 keramahan dan willing to help adalah hal - hal yang berakaitan dengan kemampuan untuk memberikan pelayanan yang dijanjikan dengan segera dan memuaskan. 
4.1.4. Hubungan antara kemudahan informasi dengan loyalitas

Hasil analisis hubungan antara loyalitas pasien dengan kemudahan informasi diperoleh bahwa dari 48 reponden yang akan loyal dengan pelayanan $\mathrm{MCU}$, ada sebanyak 42 responden $(82,4 \%)$ menyatakan kemudahan informasi yang baik, diantaranya adalah tentang informasi paket pemeriksaan yang diperoleh dan jalur evakuasi yang jelas sedangkan yang menyatakan kemudahan informasi tidak baik ada 6 responden (16,2\%), keluhan responden adalah tentang tidak adanya papan petunjuk arah ruangan dan informasi alur MCU yang belum jelas. Kemudahan informasi dalam pelayanan MCU berpengaruh terhadap loyalitas pasien.

Hasil uji statistic hubungan antara kemudahan informasi dengan loyalitas pasien medical check up diperoleh $p$-value 0.000 dimana $p$ value $\leq a(0,05)$, yang artinya ada hubungan yang signifikan antara kemudahan informasi terhadap loyalitas pasien medical check up. Nilai OR 24,111 artinya responden menyatakan kemudahan informasi yang baik mempunyai peluang 24 kali lebih loyal dibandingkan dengan responden yang menyatkan kemudahan informasi yang tidak baik.

Hasil analisa diperkuat oleh penelitian dari Dwi Zaniarti 2011, diperoleh nilai $p=0,000$. Maka hipotesis kerja yang diajukan diterima yaitu ada hubungan yang sangat significan antara pelayanan kesehatan dengan kepuasan pasien demikian dengan 2010 Jelvi Sitayani (2010) dimana hasil uji statistic diperoleh $p$ value $=0,000$ yang artinya ada hubungan signifikan antara kepuasan pasien dengan loyalitas pasien rawat jalan.

Menurut Daryanto \& Setyobudi 2014 salah satu mutu pelayanan adalah keterbukaan informasi dan memberikan kemudahan pelanggan untuk mendapatkan pelayanan kesehatan yang maksimal dan memuaskan.

\subsubsection{Hubungan antara kenyamanan dengan loyalitas}

Hasil analisis hubungan antara loyalitas pasien dengan Kenyamanan diperoleh bahwa dari 48 reponden yang akan loyal dengan pelayanan MCU, ada sebanyak 36 responden $(81,8 \%)$ yang menyatakan kenyamanan ruangan baik sedangkan yang menyatakan kenyamanan ruangan tidak baik ada 12 responden (27,3\%). 
Kenyamanan ruang $\mathrm{MCU}$ yang tersedia adalah ruang tunggu, kerapihan dan kebersihan yang terjaga, penerangan yang cukup, akan tetapi diantara pasien yang loyal hal yang sangat di keluhkan adalah jumlah ruang ganti yang tergabung dengan toilet sehingga dapat mengurangi nilai kenyamanan yang dapat mempengaruhi loyalitas pelanggan.

Hasil uji statistic hubungan antara waktu tunggu dengan loyalitas pasien medical check up diperoleh $p$-value 0.000 dimana $p$ value $\leq a(0,05)$, yang artinya ada hubungan yang signifikan antara kenyamanan ruangan terhadap loyalitas pasien medical check up. Nilai OR 12,000 artinya responden menyatakan kenyamanan ruangan yang baik mempunyai peluang $12 \mathrm{kali}$ lebih loyal dibandingkan dengan responden yang menyatkan kenyamanan ruangan tidak baik.

Hasil analisa diperkuat oleh penelitian Raden Chandra (2010) dimanana hasil uji statistic diperoleh $p$ value $=0,002$ yang artinya ada hubungan yang signifikan antara kepuasan secara umum dengan loyalitas responden, demikian menurut Ertika Sekarningrum 2016 dimana hasil uji statistic diperoleh $p$ value $=0,000$ yang artinya ada hubungan signifikan antara kemudahan layanan dengan loyalitas pasien. Menurut Parasuraman (Tjiptono,2012) kenyamanan, kelengkapan fasilitas berperan penting dalam menentukan kualitas pelayanan.

\section{SIMPULAN}

a. Hasil penelitian menunjukkan bahwa antara proporsi jumlah pasien yang loyal dan tidak loyal tidak terlalu besar, dimana pasien yang berpotensi loyal dengan pelayanan MCU di klinik medika plaza sebanyak 48 orang (54,5\%) dan yang tidak loyal sebanyak 40 orang $(45,5 \%)$.

b. Responsiveness berdasarkan aspek waktu tunggu, kemudahan layanan registrasi, keramahan, kemudahan informasi dan kenyamanan diperoleh $\mathrm{p}$-value 0.001 dimana $p$ value $\leq a(0,05)$ yang artinya ada hubungan yang signifikan antara variabel tersebut terhadap loyalitas pasien medical check up

\section{DAFTAR PUSTAKA}

1. Jayanti, N. D. (2016). Kualitas pelayanan Premium di RS tidar bantul yogyakarta. Jurnal skripsi FKM.

2. Newsletter. (2016) www.integra.co.id. Diambil kembali dari Medical Check Up: 
Https//www.integra.co.id/wpconten/mcu-perusahaan.

6. Setiawan Supriadi. (2011). Loyalitas

3. Permenkes. (2014). Peraturan Pelanggan Jasa. Penerbit IPB Press:

Mentri Kesehatan Republik Bogor.

Indonesia Nomor 58 Tahun 2014.

Tentang Strandar Pelayanan

Kefarmasian Di Rumah Sakit.

Departemen Kesehatan Republik Indonesia: Jakarta.

4. Pohan. (2007). Jaminan Mutu Pelayanan Kesehatan. Kesaint Blane, Bekasi.

5. Sari, Ratna. (2010). Hubungan Antara Kualitas Pelayanan Medichal Check Up Dengan Tingkat Pemenuhan Harapan Pejabat Bank BI. Jurnal Skripsi FKM.

7. Sugiono. (2016). Metodologi Penelitian Kuantitatif, Kualitatif dan R\&D. Bandung: CV Alfabeta. Ghozali.

8. Thamrin dan Tantri, F. (2013). Manajemen Pemasaran. Jakarta: PT Raja Grafindo Persada.

9. Tjiptono, F. (2012). Manajemen Jasa. Andi Offset: Yogyakarta. 